NOTICE: this is the author's version of a work that was accepted for publication in the journal Tetrahedron Letters. Changes resulting from the publishing process, such as peer review, editing, corrections, structural formatting, and other quality control mechanisms may not be reflected in this document. Changes may have been made to this work since it was submitted for publication. A definitive version was subsequently published in the journal Tetrahedron Letters, Vol.55, No.50 (2014). DOI: http://doi.org/10.1016/j.tetlet.2014.10.100 


\section{Graphical Abstract}

$\begin{aligned} & \text { Activation of DMSO for Swern-type } \\ & \text { oxidation by 1,1-dichlorocycloheptatriene } \\ & \text { Thanh Vinh Nguyen, Michael Hall }\end{aligned}$
Swern-type oxidation
base, $\mathrm{CH}_{2} \mathrm{Cl}_{2}$


Tetrahedron Letters

journal homepage: www.elsevier.com

\title{
Activation of DMSO for Swern-type oxidation by 1,1-dichlorocycloheptatriene
}

\author{
Thanh Vinh Nguyen,* Michael Hall \\ Department of Chemistry, Curtin University, Perth, WA 6102, Australia
}

\section{ARTICLE INFO}

\section{Article history:}

Received

Received in revised form

Accepted

Available online

Keywords:

Swern oxidation

Cycloheptatriene

Tropylium ions

Aromatic cations

Alcohol oxidation

\section{ABSTRACT}

A new dimethylsulfoxide activation method employing 1,1-dichlorocycloheptatriene has been developed for a mild Swern-type oxidation of a variety of alcohols. The carbonyl products can be obtained in good to excellent yields from this operationally simple and efficient method. This work is the first report of dimethylsulfoxide activation by a simple chlorinated hydrocarbon reagent, which has the unique ability of equilibrating to its reactive aromatic cationic form.

2014 Elsevier Ltd. All rights reserved.

The oxidation of alcohols to their corresponding carbonyl compounds is a frequently employed fundamental organic transformation in synthetic laboratories and the chemical industry. ${ }^{1}$ One of the most historic and widely used methods for alcohol oxidation involves the activation of dimethylsulfoxide (DMSO) by a variety of electrophilic reagents such as oxalyl chloride (Swern oxidation), dicyclohexylcarbodiimide (PfitznerMoffat), $\mathrm{SO}_{3}$.pyridine (Parikh-Doering), trifluoroacetic acid anhydride (Omura-Sharma-Swern) and $N$-chlorosuccinimide (Corey-Kim oxidation with dialkyl sulfide). ${ }^{2}$ Among these DMSO-activation methods, Swern oxidation has regularly been the default pathway due to its consistent efficiency over a broad range of substrates. ${ }^{2}$ The original Swern oxidation employed oxalyl chloride to form the reactive chlorodimethylsulfonium chloride, which subsequently reacted with alcohols and bases to give the carbonyl compounds and dimethyl sulfide. ${ }^{3}$ The activation of DMSO by oxalyl chloride is strongly exothermic and violently generates toxic gases such that it has to be carried out at very low temperature in a well-ventilated area. ${ }^{2-4}$ Furthermore, oxalyl chloride itself is a volatile toxic reagent that can be difficult to handle. There have been several studies investigating other chloride-bearing reagents for the replacement of oxalyl chloride in Swern-type oxidation reactions, most notably cyanuric chloride ${ }^{4}$ and triphenylphosphine dichloride. ${ }^{1}$ These reagents consist of reactive chlorides bonding to a heterocycle (cyanuric six-membered ring) or heteroatom (phosphorus in phosphine dichloride). Herein, we report the use of 1,1-dichlorocycloheptatriene (1) (Scheme 1), a simple chlorinated hydrocarbon, as a new DMSO activator for efficient Swern-type oxidation of a broad range of alcohol substrates under mild reaction conditions.
Previously, our group has reported the use of 1,1dichlorocycloheptatriene ${ }^{5}$ to activate nucleophilic substitution reactions of alcohols and carboxylic acids. ${ }^{6}$ The principle behind the activity of this compound is its ability to equilibrate between the neutral cycloheptatriene and the aromatic tropylium cation forms, which provides the driving force for nucleophilic reactions to occur. ${ }^{6}$ On this basis, we were interested to investigate the possibility of utilizing 1,1dichlorocycloheptatriene (1) to activate other systems than just carboxylic acids and alcohols. Encouragingly, preliminary experiments in our group have shown that $\mathbf{1}$ can rapidly convert DMSO into its 'Swern oxidation' active form of chlorodimethylsulfonium chloride $\mathbf{3}$. To our knowledge, this is the first use of an allyl/aryl chloride reagent such as $\mathbf{1}$ for this type of transformation, offering a mild and convenient alternative to the classical Swern oxidation.

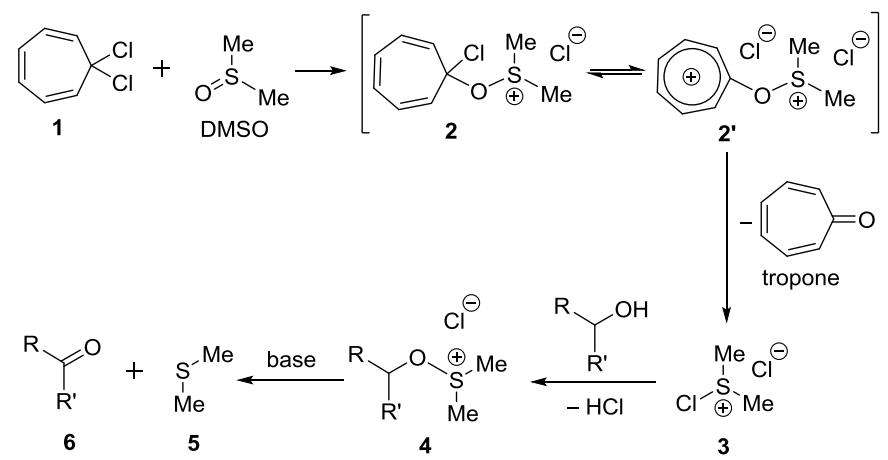

Scheme 1. Activation of DMSO for Swern-type oxidation by 1,1dichlorocycloheptatriene (1). 
We postulate that the reaction between $\mathbf{1}$ and DMSO proceeds via the sulfonium ether intermediate $\mathbf{2}$, which presumably equilibrates with the tropylium sulfonium ether intermediate 2' as mentioned earlier. The tropylium moiety of intermediate 2' has the tendency to revert back to its cycloheptatriene (tropone) form, which provides the driving force for the formation of chlorodimethylsulfonium chloride 3 . The transformations leading to 3 were extremely fast even at $-40{ }^{\circ} \mathrm{C}$, such that we were unable to obtain structural evidence for the formation of intermediates 2/2' by NMR, MS or TLC at this stage. However, these types of intermediates have been observed in our previous work on nucleophilic chlorination of alcohols using 1. ${ }^{6}$ Singh and Giacomelli also proposed similar intermediates for their activation of DMSO by triphenylphosphine dichloride ${ }^{1}$ and cyanuric chloride, ${ }^{4}$ respectively.

From this point onward, the process is analogous to the classical Swern oxidation. Treatment of an alcohol with the in situ generated chlorodimethylsulfonium chloride led to the alkoxydimethylsulfonium chloride intermediate 4, which was transformed into dimethyl sulfide (5) and the carbonyl compound 6 upon the addition of a base.

Optimization of the reaction conditions for the Swern-type oxidation of alcohols by 1,1-dichlorocycloheptatriene and DMSO was carried out with 2-phenylethanol (Table 1). ${ }^{7}$ Initially, DMSO (5.0 equiv.) was added to a solution of 1 (1.5 equiv.) in dichloromethane at $-78^{\circ} \mathrm{C}$ and the mixture was stirred at that temperature for 20 minutes. 2-Phenylethanol was then added and stirring was continued for another 20 minutes. Triethylamine (5.0 equiv.) was subsequently added, and the mixture was allowed to warm to room temperature with stirring. We were able to isolate the aldehyde product directly from a concentrated reaction mixture by column chromatography with an excellent yield of $96 \%$ (entry 1, Table 1). Varying the 'waiting' activation time from 20 minutes to 10 or five minutes had a negligible effect on product yield. The system proved to be efficient at an increased temperature up to $-30{ }^{\circ} \mathrm{C}$, but the yield of the product decreased significantly above $-20^{\circ} \mathrm{C}$ (entries $2-5$, Table 1 ). At $-30{ }^{\circ} \mathrm{C}$, the amounts of 1, DMSO and triethylamine could be reduced to 1.2, 3.0 and 3.0 equivalents, respectively without any noticeable decrease in the yield (entries 6-9, Table 1). The replacement of triethylamine by Hünig's base led to a comparable yield of isolated product, offering an alternative base for this reaction system in the event of triethylamine-sensitive products. ${ }^{8}$

These optimum reaction conditions were subsequently employed to oxidize a range of primary and secondary alcohols (Table 2). The Swern-type oxidation reactions for these
Table 1. Optimization of the reaction conditions ${ }^{\mathrm{a}}$

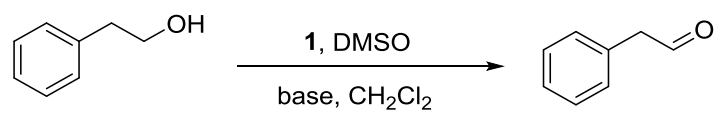

\begin{tabular}{cccccc}
\hline Entry & $\mathbf{1}$ & DMSO & Base & Temp. & Yield $^{\mathrm{b}}(\%)$ \\
\hline 1 & 1.5 equiv. & 5.0 equiv. & $\mathrm{Et}_{3} \mathrm{~N}, 5.0$ equiv. & $-70^{\circ} \mathrm{C}$ & 96 \\
2 & 1.5 equiv. & 5.0 equiv. & $\mathrm{Et}_{3} \mathrm{~N}, 5.0$ equiv. & $-30{ }^{\circ} \mathrm{C}$ & 93 \\
3 & 1.5 equiv. & 5.0 equiv. & $\mathrm{Et}_{3} \mathrm{~N}, 5.0$ equiv. & $-20{ }^{\circ} \mathrm{C}$ & 71 \\
4 & 1.5 equiv. & 5.0 equiv. & $\mathrm{Et}_{3} \mathrm{~N}, 5.0$ equiv. & $0{ }^{\circ} \mathrm{C}$ & 42 \\
$5^{\mathrm{c}}$ & 1.5 equiv. & 5.0 equiv. & $\mathrm{Et}_{3} \mathrm{~N}, 5.0$ equiv. & $25{ }^{\circ} \mathrm{C}$ & - \\
6 & 1.5 equiv. & 3.0 equiv. & $\mathrm{Et}_{3} \mathrm{~N}, 5.0$ equiv. & $-30{ }^{\circ} \mathrm{C}$ & 92 \\
7 & 1.5 equiv. & 5.0 equiv. & $\mathrm{Et}_{3} \mathrm{~N}, 3.0$ equiv. & $-30{ }^{\circ} \mathrm{C}$ & 90 \\
8 & 1.5 equiv. & 3.0 equiv. & $\mathrm{Et}_{3} \mathrm{~N}, 3.0$ equiv. & $-30{ }^{\circ} \mathrm{C}$ & 90 \\
9 & 1.2 equiv. & 3.0 equiv. & $\mathrm{Et}_{3} \mathrm{~N}, 3.0$ equiv. & $-30{ }^{\circ} \mathrm{C}$ & 91 \\
10 & 1.2 equiv. & 3.0 equiv. & ${ }^{i} \mathrm{Pr}_{2} \mathrm{NEt}, 3.0$ equiv. & $-30{ }^{\circ} \mathrm{C}$ & 92 \\
\hline
\end{tabular}

${ }^{\text {a }}$ See the Supporting Information for the reaction conditions.

${ }^{\mathrm{b}}$ Yield of isolated product.

${ }^{\mathrm{c}}$ Only a trace of the carbonyl product was observed.

substrates occurred smoothly, affording the corresponding carbonyl compounds in good to excellent yields. ${ }^{7}$ Functional groups on benzylic alcohols seemed to have an insignificant effect on the outcomes of the reactions (entries 1-5, Table 2). There was no noticeable difference in the reactivity between activated alcohols and non-activated alcohols (entries 6-9, Table 2) or cyclic/acyclic alcohols (entries 13 and 14, Table 2). Oxidation of secondary alcohols seemed to afford slightly lower yields of isolated products compared to those obtained with primary alcohols. Albeit with somewhat lower yields, the oxidation of diol and heterocyclic alcohol substrates also proceeded smoothly under the developed reaction conditions (entries 10-12 and 21, Table 2). Biologically relevant substrates such as $\beta$-ionol and (-)-menthol (entries 22 and 23, Table 2) were also oxidized to their corresponding ketones in high yields without structural rearrangement or epimerization. ${ }^{7}$ The products could be isolated by the direct column chromatography of the concentrated reaction mixtures. The valuable tropone by-product could be recovered from these reaction mixtures in $71-92 \%$ yields. ${ }^{7}$

Table 2. Swern-type oxidation of various alcohol substrates to give the corresponding carbonyl compounds ${ }^{\mathrm{a}}$

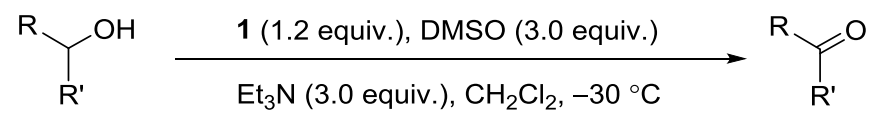

Entry Substrate Substrate


<smiles>OC/C=C/c1ccccc1</smiles><smiles>O=C/C=C/c1ccccc1</smiles><smiles>CCCCCCCCCO</smiles><smiles>CCCCCCCC=O</smiles><smiles>OCCc1ccccc1</smiles><smiles>O=CCc1ccccc1</smiles>

9<smiles>OCCCc1ccccc1</smiles><smiles>O=CCCc1ccccc1</smiles><smiles>OCc1cccnc1</smiles><smiles>[AlH]</smiles><smiles>OCc1ccccn1</smiles>

12<smiles>OCc1ccc(CO)cc1</smiles><smiles>O=Cc1ccc(C=O)cc1</smiles><smiles>OC1c2ccccc2-c2ccccc21</smiles><smiles>OC(c1ccccc1)c1ccccc1</smiles><smiles>Cc1ccc(C(O)c2ccccc2)cc1</smiles>

21<smiles>O=Cc1cccnc1</smiles><smiles>O=C1c2ccccc2-c2ccccc21</smiles><smiles>O=C(c1ccccc1)c1ccccc1</smiles><smiles>Cc1ccc(C(=O)c2ccccc2)cc1</smiles><smiles>CC(=O)/C=C/C1=C(C)CCCC1(C)C</smiles>

86
${ }^{a}$ See the Supporting Information for the reaction conditions.

${ }^{\mathrm{b}}$ Yield of isolated product.

The advantages that this new activation method has over the classical Swern oxidation reaction are: (1) the reaction between 1 and DMSO was operationally simple and gentle; (2) it generated no gaseous toxic by-products; (3) The tropone by-product can be isolated in high yield and recycled to produce $\mathbf{1}$ again, ${ }^{5,6}$ making the method cost-efficient for application in synthetic laboratories. 1,1-Dichlorocycloheptatriene (1) has been shown to convert primary and secondary alcohols to their chloride derivatives, ${ }^{6}$ however, there was no trace of these competing reaction products in all the cases reported in Tables 1 and 2, as was predicted by employing an excess of DMSO and a low reaction temperature.

In conclusions, we have developed a new and alternative method to activate DMSO for the mild and efficient Swern-type oxidation of alcohols to their corresponding carbonyl compounds. This is the first report on employing an allyl/aryl chloride such as 1,1-dichlorocycloheptatriene (1) to activate DMSO. The method presumably relies on the unique ability of the chlorocycloheptatriene moiety to equilibrate with its reactive tropylium chloride form. ${ }^{6}$ This study not only offers a versatile alternative to the classical Swern oxidation but also expands the scope of tropylium aromatic cation chemistry pioneered by our group beyond nucleophilic substitution reactions of hydroxyl groups. ${ }^{6}$ Studies to apply this new DMSO activation method to other types of chemical transformations ${ }^{10}$ are ongoing and will be reported in due course.

General procedure for the Swern-type oxidation reaction: A solution of DMSO $(3.0 \mathrm{mmol})$ in $\mathrm{CH}_{2} \mathrm{Cl}_{2}(2.0 \mathrm{~mL})$ was added to a solution of $1(1.2 \mathrm{mmol})$ in $\mathrm{CH}_{2} \mathrm{Cl}_{2}(5.0 \mathrm{~mL})$ at $-30{ }^{\circ} \mathrm{C}$, and the mixture was stirred for $20 \mathrm{~min}$ at the same temperature. The alcohol substrate $(1.0 \mathrm{mmol})$ was added, and the mixture was stirred for another $20 \mathrm{~min}$ before the dropwise addition of $\mathrm{Et}_{3} \mathrm{~N}$ $(3.0 \mathrm{mmol})$. The mixture was subsequently left to warm to room temperature (20 mins) and concentrated under reduced pressure. The product was isolated by flash column chromatography.

Acknowledgments: We thank Curtin University for funding this research project. Generous laboratory support and helpful discussions from Dr. Alan Payne (Curtin) are gratefully acknowledged.
${ }^{c} 2.2$ equiv. of 1,5.0 equiv. each of DMSO and $\mathrm{Et}_{3} \mathrm{~N}$ were used.

${ }^{\mathrm{d}}$ No trace of epimerized products.

Supplementary Material: Experimental procedures and product characterization data are available in the Supporting Information.

\section{References and notes}

1. Bisai, A.; Chandrasekhar, M.; Singh, V. K. Tetrahedron Lett. 2002, 43, 8355-8357.

2. Tojo, G.; Fernandez, M. I. Oxidation of Alcohols to Aldehydes and Ketones: A Guide to Current Common Practice, Springer, New York, 2006 and references therein.

3. Omura, K.; Swern, D. Tetrahedron 1978, 36, 1651-1660.

4. Luca, L. D.; Giacomelli, G.; Porcheddu, A. J. Org. Chem. 2011, 66, 7907-7909.

5. 1,1-Dichlorocycloheptatriene (1), see ref. 6, can be synthesized from cycloheptatriene by hydride abstraction/chlorination or treatment of tropone with various chloride sources. It can be stored in solid form under an inert environment in the fridge or in dichloromethane solution on the bench for months without significant degradation.

6. Nguyen, T. V.; Bekensir, A. Org. Lett. 2014, 16, 1720-1723.

7. See the Supporting Information for more details.

8. $\mathrm{Et}_{3} \mathrm{~N}$ reportedly caused $\alpha$-epimerization and rearrangement of some carbonyl products. These side reactions can be prevented by using the bulkier Hünig's base, see: (a) Walba, D. M.; Thurmes, W. N.; Haltiwanger, R. C. J. Org. Chem. 1988, 53, 1046-1056; (b) Evans, D. A.; Polniaszek, R. P.; De Vries, K. M.; Guinn, D. E.; Mathre, D. J. J. Am. Chem. Soc. 1991, 113, 7613-7630; (c) Evans, D. A.; Gage, J. R.; Leighton, J. L. J. Am. Chem. Soc. 1992, 114, 9434-9453; (d) Evans, D. A.; Ripin, D. H. B.; Halstead, D. P.; Campos, K. R. J. Am. Chem. Soc. 1999, 121, 6816-6826; (e) Hu, T.-S.; Yu, Q.; Wu, Y.-L.; Wu, Y. J. Org. Chem. 2001, 66, 853861; (f) Longbottom, D. A.; Morrison, A. J.; Dixon, D. J.; Ley, S. V. Angew. Chem. Int. Ed. 2002, 41, 2786-2790.

9. 1,1-Dichlorocycloheptatriene (1) can efficiently convert alcohols into the corresponding chlorides only at room temperature or at elevated temperature. See ref. 6 for more details.

10. Chlorodimethylsulfonium chloride (3) and its analogues can also be employed as an oxidant/chlorinating reagent in other chemical transformations. For selected recent literature examples, see: (a) Yin, J.; Gallis, C. E.; Chisholm, J. D.; J. Org. Chem. 2007, 72, 7054-7057; (b) Lopez-Alvarado, P.; Steinhoff, J.; Miranda, S.; Avendano, C.; Menendez, J. C. Tetrahedron 2008, 65, 1660-1672; (c) Deng, Y.; Kin, X.; Fu, C.; Ma, S. Org. Lett. 2009, 11, 21692172; (d) Wyman, J.; Javed, M. I.; Al-Bataineh, N.; Brewer, M. J. Org. Chem. 2010, 75, 8078-8087. 